\title{
Young children's perceptions of branded healthy fast food
}

\author{
by Kellershohn, J., Walley, K. and Vriesekoop, F.
}

Copyright, Publisher and Additional Information: This is the author accepted manuscript. The final published version (version of record) is available online via Emerald Publishing.

This version is made available under the CC-BY-ND-NC licence:

https://creativecommons.org/licenses/by-nc-nd/4.0/

Please refer to any applicable terms of use of the publisher

DOI: https://doi.org/10.1108/BFJ-01-2018-0002

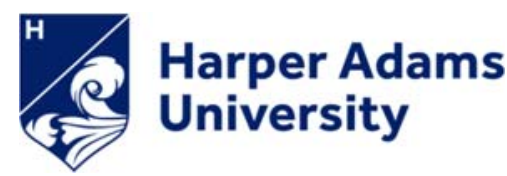

Kellershohn, J., Walley, K. and Vriesekoop, F. 2018. Young children's perceptions of branded healthy fast food. British Food Journal. 


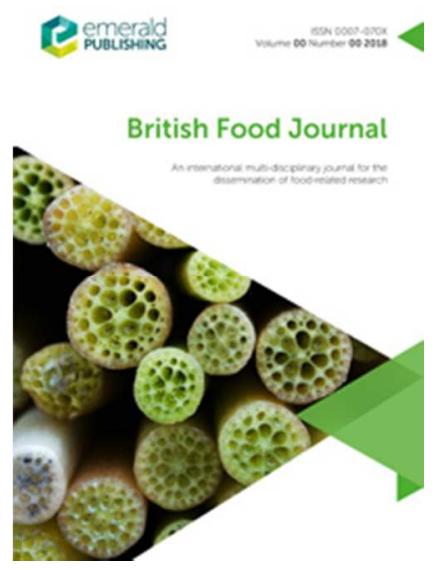

Young children's perceptions of branded healthy fast food

\begin{tabular}{|r|l|}
\hline Journal: & British Food Journal \\
\hline Manuscript ID & BFJ-01-2018-0002.R1 \\
\hline Manuscript Type: & Research Paper \\
\hline Keywords: & Parents, Fast food, Card Sort, Food Choice, Health, Children \\
\hline \multicolumn{2}{|l}{} \\
\hline
\end{tabular}

SCHOLARONE ${ }^{m}$

Manuscripts 


\section{Young Children's Perceptions of Branded Healthy Fast Food}

\section{Structured Abstract}

Purpose - This study examined the role of branding on healthy fast food items.

Design/methodology/approach - Twenty children (age 4 to 6) performed one open sort and four closed card sorts about food preferences, perceived healthiness, and perceived parental preferences, using branded and non-branded food image cards. Descriptive statistics were calculated and major themes were identified from the verbatim transcripts.

Findings - The children chose whole fruit over branded and bagged apple slices, stating whole fruit would be tastier, healthier, and more likely parents approved. When apples were sliced and bagged, perceived taste and healthiness perceptions were variable. Packaged foods were more challenging for the children to conceptualize. Presented with eight options, french fries were the favourite choice as the children did not believe fruit or vegetable side dishes should accompany a cheeseburger.

Research limitations/implications - Only children's perceptions and not actual eating behaviours were measured. It was a small sample $(n=20)$ with limited sample diversity that would not be representative of all children.

Practical implications - Packaging and branding a healthy food item with a fast food logo did not increase the item's appeal to the children. Branding healthy foods in this manner may not lead to increased consumption.

Originality/value - The impact of branding healthy items on very young children's perceptions has rarely been examined. Most of the research on branded food items has focused on high calorie processed foods. Using a card sort exercise allowed children, too young to read and write, to articulate similarities, differences, and motivations around food preferences.

Keywords Parents, Health, Children, Fast Food, Branding, Food Choice, Card Sort, McDonald's

Paper type Research paper 


\section{Introduction}

\section{Children and fast food}

The Quick Service Restaurant (QSR) industry (commonly referred to as the fast food industry) plays an important role in the dietary intake of children (Castro et al., 2016). The frequency with which children eat away-from-home food has been on the rise since the beginning of this century (Poti and Popkin, 2011; Powell et al., 2012). In the US, just over one third of children consume fast food on a given day, and one out of eight children obtain more than $40 \%$ of their daily calories from fast food (CDC, 2015).

French fries are the common default side dish for a child's fast food meal. Depending on the restaurant, alternative side dish options are often available such as apple slices, orange segments, and yogurts (Shonkoff et al., 2018). The fast food restaurant industry has responded to consumer pressure to introduce more healthy side options with children's meals (Anzman-Frasca et al., 2014; Lee et al., 2016), however, various studies have shown that consumer uptake of the healthier side options has been minimal (Dodds et al., 2014) and the majority of children's meals fail to meet current nutritional recommendations (Sliwa et al., 2016).

Increased autonomy for food decisions outside of the home accelerates after age six. Prior to age seven, parents remain the primary gate keeper of food related decisions, when the children have not yet entered the phase of more autonomous food choices (Tinsley, 2003). The majority of the published research on young children dining outside of the home has been focused on surveying school aged children rather than preschool aged children. However, many of a child's long-term eating habits are formed in the early years (Wansink, 2015). The first six years of life are a critical time in the development of food preferences, when parents have a key influencing role, and when established food preferences have long term implications as to what the child will continue to eat once they reach an age of food decision autonomy. There is sparse literature on consumer behaviour related to ordering for young children in fast food restaurants (Kennon and Reynolds, 2001) and menu labelling with calories has not been shown to shift ordering habits (Sacco et al., 2016). A better understanding is required of how current fast food meal options are viewed. This study aims to further the understanding children's perceptions, during this transitional age (4-6 years old), from shared decision making (parent/child) to independent decision making.

\section{Branded food}

Research has shown mixed results when examining branded food items and children's food preferences and consumption patterns. Gelperowic and Beharrell (1994) addressed the role of the packages appeal to children and mothers' purchase decisions for healthy food products. Hartman (2017) examined branded snack choices of children (age 8 to 11) and demonstrated that preference by product type is the greatest influence on children's snack purchase decisions. A child's liking of a brand determines whether a brand is successful at motivating a child of this age to choose a product.

Keller et al. (2012) tested decorating fruit and vegetable containers with stickers of cartoon characters and provided prizes for fruit and vegetable consumption. Parents were instructed to offer a fruit and/or vegetable of the child's choosing at meals (three times per day) and 
one additional offer at snack time to the children $(n=7)$ (age 4 to 5 ). A measured increase in fruit and vegetable consumption was observed under these stringent conditions.

Robinson et al. (2007) demonstrated that branding could change a child's taste perceptions. Sixty-three children (age 3 to 5) took part in a tasting experiment. Results indicated that they were more likely to prefer the taste of chicken nuggets, french fries, milk, apple juice and carrots, if they were branded McDonald's, compared to unbranded identical foods.

Food marketing is primarily used to promote energy-dense, nutrient-poor foods. With children as young as 4 years of age able to recognize brands (McAlister and Cornwell, 2010; Watkins et al., 2017), and branded products having been shown to influence food preferences, it was of interest to study whether the branding used for fast foods could have a positive (or negative) impact on the perceptions of some healthy foods.

\section{Card sorts and food assessment with children}

Card sorts are used to explore how people organize and map objects and ideas (Fincher and Tenenberg, 2005). When working with young children, who are not yet of an age when they can read or write fluently, a card sort exercise is easy to administer, has a short learning curve, does not require literacy skills, and is an engaging process for children (Wiseman and Harris, 2015). Card sorts have been used with young children to demonstrate how they characterize foods from their own perspectives (Wiseman and Harris, 2015; Adams and Savage, 2017).

While this technique limits participants to the items depicted in the card deck, including an open sort (no structured categories) with the closed sorts (structured categories), it allows for the children to freely categorize the items into their own groupings, providing grounded insights into how the cards cluster. Card sorts, in food research with children, are one approach to understand how children categorize foods (Beltran et al., 2008; Sepulveda et al., 2009; Weller and Romney, 1988). While some research has looked at children aged 8 to 11, and tied product type, brand, and pricing together (Hartmann et al., 2017), less research has been conducted with younger children (aged 4 to 6 ), for whom the images of the options may be more influential.

The goal of this exploratory study was to examine young children's perspectives of branded and unbranded foods, by using card sorts, to explore how they categorize the foods, and to evaluate and describe their choices. Understanding the role that branding healthy food items may play, could help in the promotion of healthy side dishes for children in fast food restaurants.

\section{Methods}

\section{Respondents}

A total of 20 children (age 4 to 6 ) participated in the study. They were recruited from a convenience sample in Toronto, Canada, in 2017. The sample size was limited to 20 , at which no new themes appeared to be emerging. Eligibility criteria included no dietary restrictions and a familiarity with eating in fast food restaurants. One parent of each participant provided written informed consent and at least one parent was present during the card sort exercise. The research was conducted in the participant's home, to provide the 
child with a familiar environment. Parents provided a quiet space for the interview, either at the dining room table or on the floor of the living room. Space was cleared so that the child had ample room to sort the cards. Distractions were minimized (no TVs, tablets, or music playing), with no branded food items within line-of-sight. During the card sort exercise, a parent was within viewing distance of the child, but out of the child's line of sight, to minimize parental influence. No participation incentive was provided. The study was approved by the $<$ University Name to be added after blinded peer review process> University Research Ethics Board.

\section{Background}

The card sorts were used to assess children's perceptions of branded and unbranded healthy food items. This study is a part of a larger ongoing project investigating family dining practices in fast food restaurants.

\section{Card design and sort}

Two card decks were developed by the researchers and the cards were pilot tested with two children. Cards were colour-printed on laminated card stock $(8 \mathrm{~cm} \times 8 \mathrm{~cm})$. Cards were sized to be easy for a 4 to 6 -year-old child to hold and sort. The card sort activity involved the child sorting a deck of cards that were pre-printed with photos of food items. Cards were sorted into an open sort first (with groups created by the child) and then into a series of closed sorts (with groups predetermined by the researcher).

\section{Card sort deck one}

The first card sort deck was a single food item (an apple) in seven forms. There were three unbranded formats: a whole apple, apple slices, and apple slices in an opaque snack sized unbranded bag and four branded apple slices in opaque snack sized bags (Figure 1).

$<$ Fig.1>

The opaque bag format was chosen as it is a common format for selling apple slices in fast food restaurants and in grocery stores in Canada, and the children would be familiar with this format. Five options were included in the apple slices-in-a-bag format, including: unbranded (labelled "Apples Slices"), one with a generic cartoon apple logo, and three versions using common QSR brands that have offered apple-in-a-bag options. These were McDonald's, Starbucks, and Subway. The design of the apple slices-in-a-bag images were identical, except for the logo.

\section{Card sort deck two}

The second card sort deck was comprised of nine different common food items. Examples of the cards are shown in Figure 2.

$<$ Fig.2>

The items chosen were common offerings available in fast food children's meals: whole apple, sliced apple, whole orange, orange segments, baby carrots, cheeseburger, french fries, yogurt cup. The images were designed to be comparable in perceived size. For example, there were seven slices of apple on the card with the apple slices on it, which is the equivalent of one whole apple, and on the card with the baby carrots, there were also seven baby carrots, so that the number of food pieces did not bias the response. In addition, an image of brussels sprouts was included in the deck. While brussels sprouts are not 
offered in a fast food child's meal, the image was intended to provide an anchor point of reference for the child.

Visual scale

A third series of cards (Figure 3) was used for the closed card sorts, to provide participants with a visual hedonic response scale.

$<$ Fig.3>

This response option was designed based on commonly used scales for this purpose (ASTM E2299-03) appropriate for children and easy to understand. Emoticons have become popular worldwide on smartphones, social media, and email applications (Novak et al., 2015). Jaeger et al. (2017) demonstrated that emojis can be used to measure the appreciation of foods in a subjective, non-verbal manner. Gallo et al. (2017) demonstrated that children can use a combination of emotion words and emojis to describe their reactions to foods. A scale of emoji-type faces is not new to food research with children, as over 20 years ago, Chen et al. (1996) used a version of this scale to study food preferences in young children. A 5-point scale of emoticon faces was used to represent a 5-point measurement scale for the closed card sorts. For each of the four closed sorts, the interviewer identified what the ends of the scale represented, for example, for the first closed sort, children sorted food based on what they thought tasted 'good/yummy' to food they thought tasted 'not good/yucky'.

Interviews

During the interviews, participants completed a series of five card sorts per deck, 10 sorts in total. Five sorts were completed with deck one, followed by five sorts with deck two. Given the young age of the participants, the number of cards was intentionally limited, and the length and depth of the interview was guided by the engagement of the child.

The interview began with an open sort, with no structured categories, followed by four sorts with closed categories. The five sorts were as follows.

1. Open methods sort: the child sorted the food cards into groups of their choice.

After the open methods sort, for the closed sorts, the visual scale was added to the work space to assist the child in the sort.

2. Closed methods sort: the child sorted the food cards into piles based on taste (best taste to worst taste).

3. Closed methods sort: the child sorted the food cards into piles based on perceived healthiness (most healthy to least healthy).

4. Closed methods sort: the child sorted the food cards into piles based on what they thought their mother would like them to eat (mom wants me to eat this to mom does not want me to eat this).

5. Closed methods sort: the child was asked if they had a second adult in their home living with them (for example, a father, a second parent). If there was a second adult in the child's home, the child was asked to sort the food cards into piles based on what the other adult might like them to eat (they want me to eat this to they do not want me to eat this). 
The cards were shuffled to achieve a random order prior to each sort. Any questions that the children had about the cards were answered by the interviewer (for example, confirming that each depicted bag had the same number of apple slices in it). For the open sort, the children could create as many or as few piles as they wanted, and a pile could have only one item if that was what the child wanted. After sorting, the interviewer asked the child to describe each pile they had created. The interview was audio recorded. Photos were taken of each card sort. The photos captured how the cards were sorted on the table and the photos were added to the field notes. No identifying characteristics of the participants were captured. After the interview, the audio file was transcribed and the sort order was captured from the field photos. Conducting the card sorts took 10 to 22 minutes per child.

Analysis

For the open methods sort, participant-described categories were compiled and coded for emergent themes and concepts. Participant comments from the transcription were reviewed to ensure that the development of the themes was consistent with the participants' descriptions.

For the closed sorts, descriptive statistics were calculated and the 5-point visual scale was converted to a quantitative score (1=Happy Face to 5=Unhappy Face) to allow for additional analytics. Frequency data and descriptive statistics for the card sort were calculated using SPSS version 24.

A grounded theory approach (Strauss and Crobin, 1994) was used to identify emerging themes from the verbatim transcripts. Participant quotes were chosen to describe each major theme, and were selected across a range of participants to ensure representation from the sample population.

\section{Results}

Participants

A total of 20 children participated in the study, 8 boys, 12 girls. Children were age 4 to 6 (mean age of 5.1 ( \pm 0.9 ) years). The children were predominantly Caucasian $(80 \%)$, and most had two parents living at home (95\%).

Deck one card sort - apples

All children recognized and easily identified the whole apple and apple slices. While they did not necessarily recognize the brands on each bag of apple slices, they were able to recognize that it was a picture of a bag of something apple-related and that it came from a store or a restaurant.

\section{Open sort exercise}

During the unstructured card sort, children were instructed to sort the apple cards into piles of things that were the same and things that were different. The children could make as many or as few piles as they wished. The children after sorting the images of apples into similar and different foods were asked to explain their groupings; 18 of the 20 children completed an identical sort. The whole apple and the slices of apple were one group and all of the bagged apples were placed in a second group. The whole apple and sliced apple were identified as the same food, but it was not always clear to the children what was in the 
apple bags. From the perspective of the children, the apples in the bags, regardless of the brand, were distinctively different from the whole apple or apple slices not in a bag.

"Is it dried apples? Apple slices? Apple sauce? I can't tell. Only that it is different from these" [points to the whole apple and the non-bagged sliced apple] (male, 5 years old)

Closed sort exercise

Most children thought that they would like the taste of the whole and sliced apples and classified both as healthy food choices. The perceptions of the sliced apples in bags demonstrated variability, as to whether the children thought the slices would taste good, if the slices were healthy, and if the slices were something that they thought a parent would want them to eat. Results the card sort are presented Figure 4, with detailed tabulated scores available in Supplementary Table I.

$<$ Fig.4>

A cumulative score can be seen in Figure 4, in which the whole apple scores higher than all the other apple variations. Of note, the cartoon branded apple has an overall higher cumulative score than the unbranded apple, elevated by what the child perceives the parent's perception of it is.

\section{Themes}

The three major themes identified from the discussions during the closed apple card sort are outlined below. The study was limited to 20 respondents, since while reinforcing themes from previous interviews, with respondents 17 to 20 no new themes arose.

\section{Theme 1: Packaged apples in a bag are not the same as non-packaged apples}

Similar to the open sort, it was clear that apples in bags were different from apples that were not in bags.

"If they are in a bag they would taste different." (female, 6 years old)

"These look like they could come from a farm [points to whole apple and sliced apple] but you would not find these on a farm. These are from a store." (male, 6 years old)

\section{Theme 2: Brand sometimes influenced expected taste and experience}

The branded apple options included McDonald's, Starbucks, and Subway, as well as an unbranded version and a version with a generic happy cartoon apple on the bag. Many of the children recognized the McDonald's logo and the Starbucks logo, but very few recognized the Subway logo. Seeing the McDonald's logo, often led to comments about what other experiences McDonald's offered.

"McDonald's! You get toys there too. Cheeseburgers, french fries and toys!" (female, 4 years old) 
While some children recognized the Starbucks logo by name, most referred to it as a coffee shop. Associating a coffee shop with apples was often not an intuitive fit for the children. For some, this meant that the apples would likely have a coffee taste.

"Those apples would taste yucky [points to Starbucks branded apple slices] because I think there's coffee there too." (female, 6 years old)

One respondent, interpreted the word Subway, for the type of underground transportation known as a subway.

"Subway? Who would eat apples on the subway? That's gross." (male, 6 years old)

\section{Theme 3: Apples are healthy, except when they are not}

Most children categorized the apples as healthy and tasty. However, all apples were not equally healthy.

For the whole apple, the children were quick to identify it as healthy $(90 \%)$ and as something a parent would want them to eat. However, for branded apple slices, the distinction was not as clear.

"This apple is from McDonald's [places apple under the unhappy face] ...McDonald's doesn't have very good food...momma doesn't want me to eat McDonald's food." (female, 6 years old)

Deck two card sort - assorted foods

All children recognized and easily identified the food items, except for the brussels sprouts, which required clarification from the interviewer at times. The children recognized the brussels sprouts, but some could not remember the name of the food.

Open sort exercise

When asked to sort the food images into similar and different foods and to explain their groupings, a few common groupings were created by the majority of the children. Whole fruit was most often partnered with its segmented counterparts, for example the whole apple was most often grouped with the apple slices and the whole orange was most often grouped with the orange segments. The brussels sprouts were rarely grouped with other items. Children commented that nothing was similar to brussels sprouts. The cheeseburger was most often grouped with the french fries, and the interviewer probed further to see if other items might be associated with the cheeseburger, but additional groupings were not identified.

"French fries go with the cheeseburger." (female, 5 years old)

Interviewer: Could anything else go with the cheeseburger?

"No, when you go to a restaurant, you get french fries with your cheeseburger."

Interviewer: Do you ever get apple slices with a cheeseburger?

"No."

Interviewer: Do you ever get carrots with a cheeseburger?

"No, only french fries go with a cheeseburger." 


\section{Closed sort exercise}

Most children liked the fruit options and identified them as healthy. French fries were most often identified as a food the child thought tasted the best, with a variety of responses as to whether or not french fries were healthy. As expected, brussels sprouts received a strong response from the children. Brussels sprouts were often identified as a food that they would not like, but as a healthy item that at least one parent would want them to eat.

Results from the assorted food card sort are presented Figure 5, with detailed tabulated scores available in Supplementary Table SII.

$<$ Fig.5>

Looking at the cumulative scores (Figure 5), even though the french fries were the option chosen by most of the children, they were ranked as one of the lowest items in terms of 'would my parent want me to eat this?'. This may well create tension in negotiating what the child eats in a fast food restaurant.

The major themes identified from the discussions during the closed assorted food card sort are outlined below.

\section{Theme 4: Tasty and healthy are distinct concepts}

For the majority of the children, french fries were identified as the tastiest of the options and were frequently referenced as the chosen option of all of the food cards. But, the children were also clear that french fries were not as healthy as the fruit options and that at least one parent would likely want them to eat fruit more frequently than french fries.

"I love French fries. I want them every day." (male, 6 years old)

"French fries are not as healthy as fruit. But they are yummy." (female, 6 years old)

\section{Theme 5: Nutrients}

While the male respondents rarely mentioned specific nutrient elements of the food images, the female respondents frequently talked about the nutrients, what was in the food, and how that influenced their opinion.

"They [pointing to french fries and cheeseburgers] aren't healthy for you...because they use sugar in them. It's bad because it's not healthy for you." (female, 6 years old)

"Bread is made of sugar and it doesn't have any vegetables so it's not good for you...[pointing to french fries] these are a little bit healthier because it has potatoes in it". (female, 5 years old)

"French fries are not healthy cause of the salt...sometimes salt makes you sick or if you have too much salt you can pass out and never wake up again." (female, 6 years old)

\section{Theme 6: Children understand that their parents have different food perspectives}

For households with two parents, the children were asked to estimate what their mother would want them to eat, or not want them to eat. Then they were asked to do an additional sort reflecting what the second adult in their house would want them to eat or not want them 
to eat. Often, the second parent was portrayed by the child as having a much more lenient approach to eating.

“When I'm out with my dad, there's no chance of getting anything healthy...because when me and my dad are out we always have party time food ...because when I'm out with him, he doesn't like having anything healthy." (female, 6 years old)

"Dad wants me to eat anything. He's just happy when I eat. It doesn't matter what it is." (male, 4 years old)

\section{Summary}

A conclusion from this study, similar to the conclusions by Adams and Savage (2017) on their snack study with this age group of children, is that we need a better understanding of young children's eating behaviour if we wish to target effective interventions for healthy eating. Althubaiti et al. (2017), looking at a wider range of ages (age 3 to 12) in a snack card sorting exercise, reported that when children were asked about their parent's snack choices for them, as in our study, they identified snacks that they perceived to be healthier. However, in their study, they observed that perceptions of healthier did not translate into the children's actual snacking behaviour and suggested that more nutrition education is required to encourage healthy choices.

Using a visual card-sorting approach, this study provides insights into young children's perceptions of branded food items offered in fast-food restaurants. Findings from the card sort revealed that children have a strong opinion of what food items will taste good, which items are healthy, and which items a parent might want them to eat and these classifications, while they may overlap, are distinct to them

Most children thought whole and sliced apples were a healthy food choice. Sliced apples in bags demonstrated variability not seen in whole or non-bagged apple slices, as to whether the children thought they would taste good, if they were healthy, and if they were something they thought a parent would want them to eat.

Whole fruit items were identified as healthy and tasting good. French fries and cheeseburgers were identified as tasting good, but with varied perceptions of health. For the children, it was more challenging to estimate how a packaged food would taste, if it was healthy and if parents would want them to eat it.

Brand logos influenced some of the children's perceptions on how a common food item would taste. However, the branding did not elevate the perception of the apple slices in the bags, in terms of taste or healthiness compared to the whole fruit.

Of the current options available for a child's meal at a fast-food restaurant, the majority of the children identified french fries as their chosen option. Regardless of the format of the fruit (whole, sliced, or branded apples or oranges), the perceived healthy items were not as appealing as the french fries, even less so once they were packaged. While the restaurants may be offering fruit side options in a child's meal, children as young as age 4 were pairing the french fries with the cheeseburger, and the majority did not pair fruit or vegetable options as naturally accompanying a cheeseburger. 
Typically, in a two-parent household, one parent had a more lenient approach to what their child should eat when dining out, and often the father was portrayed as more lenient.

Relatively few studies examine how branding might be used to increase the appeal of healthy foods among young children. This study adds to the limited body of literature in the under-researched area of parental interactions with young children ( $\leq 6$ years old) regarding fast food ordering decisions. Understanding how children perceive foods branded as healthy items and meal options in fast-food restaurants, provides a foundation for future research to better understand children's eating behaviour and how to develop more effective targeted interventions to encourage healthy choices. Additional research is needed to understand how branded healthy food items vary in perception based on a child's ethnicity, nationality, and economic status.

\section{Limitations}

A limitation of the study was that only children's perceptions and not actual eating behaviours were measured. In addition, only a small number of children were interviewed. The children were primarily English-speaking, middle class Canadians. Therefore, not a representative geographical sampling. Findings might be different using a larger pool of children, where there is a greater diversity in terms of ethnicity and socioeconomic status. The sample size and limited diversity in the sample did not allow for analysis of the results by factors such as gender, ethnicity, or socioeconomic status.

\section{Practical implications}

Children were able to clearly articulate their thoughts on the food images, and to sort them based on the 5-point scale. Children as young as four were able to recognize a brand on food packaging and to differentiate between what they think tastes good and what they think is healthy. Some were able to start to describe nutrients. Packaging and branding a healthy food item with a fast-food logo did not increase the item's appeal to children. Understanding children's perceptions of branded healthy items can help in presenting healthier options to encourage their selection. Perhaps the goal of designing a 'healthy treat' could inform future product innovations, or future meal design could consider including a default healthy item and a small treat to offer a more balanced approach

\section{References}

Adams, E. L. and Savage, J. S. (2017)," From the children's perspective: What are candy, snacks, and meals?", Appetite, Vol. 116 Sept., pp. 215-222.

Althubaiti, H., Hambly, C., Mitchell, S. E. and Speakman, J. R. (2017), "Children's perception on healthy snacks using a card sorting exercise in Aberdeenshire nursery and primary schools", Proceedings of the Nutrition Society, Vol. 76 (OCE2): E39, doi:10.1017/S0029665117000957

Anzman-Frasca, S., Dawes, F., Sliwa, S., Dolan, P.R., Nelson, M.E., Washburn, K. and Economos, C.D. (2014), "Healthier side dishes at restaurants: an analysis of children's 
perspectives, menu content, and energy impacts", International Journal of Behavioral Nutrition and Physical Activity, Vol. 11 No. 1: 81, https://doi.org/10.1186/1479-5868-11-81

ASTM E2299-03. (2003), "Standard Guide for Sensory Evaluation of Products by Children", ASTM International, West Conshohocken, PA.

Beltran, A., Sepulveda, K.K., Watson, K., Baranowski, T., Baranowski, J., Islam, N. and Missaghian, M. (2008), "Grains are similarly categorized by 8- to 13-year-old children", Journal of the American Dietetic Association, Vol. 108 No. 11, pp. 1921-1926.

Castro, I.A., Williams, C.B., Madanat, H., Pickrel, J.L., Jun, H.J., Zive, M., Gahagan, S. and Ayala, G.X. (2016), "Food ordering for children in restaurants: multiple sources of influence on decision making", Public Health Nutrition, Vol. 19 No. 13, pp. 2404-2409.

CDC (Centers for Disease Control and Prevention) (2015), "Caloric intake from fast food among children and adolescents in the United States, 2011-2012", NCHS Data Brief No. 213, September, available at: https://www.cdc.gov/nchs/data/databriefs/db213.htm (accessed 14 December 2017).

Chen, A. W., Resurreccion, A. V. A. and Paguio, L. P. (1996), "Age appropriate hedonic scales to measure food preferences of young children", Journal of Sensory Studies, Vol. 11, No. 2, pp. 141-163.

Dodds, P., Wolfenden, L., Chapman, K., Wellard, L., Hughes, C. and Wiggers, J. (2014), "The effect of energy and traffic light labelling on parent and child fast food selection: a randomised controlled trial", Appetite, Vol. 73 Feb., pp. 23-30.

Fincher, S. and Tenenberg, J. (2005), "Making sense of card sorting data", Expert Systems, Vol. 22 No. 3, pp. 89-93.

Gallo, K. E., Swaney-Stueve, M. and Chambers, D. H. (2017), "A focus group approach to understanding food-related emotions with children using words and emojis", Journal of Sensory Studies, Vol. 32 No. 3, e12264, doi: 10.1111/joss.12264

Gelperowic, R. and Beharrell, B. (1994), Healthy food products for children: Packaging and mothers' purchase decisions. British Food Journal, Vol. 96 No. 11, pp.4-8.

Hartmann, M., Cash, S. B., Yeh, C. H., Landwehr, S. C. and McAlister, A. R. (2017), "Children's purchase behavior in the snack market: Can branding or lower prices motivate healthier choices?", Appetite, Vol. 117 Oct., pp. 247 -254.

Jaeger, S. R., Vidal, L., Kam, K. and Ares, G. (2017), "Can emoji be used as a direct method to measure emotional associations to food names? Preliminary investigations with consumers in USA and China", Food Quality and Preference, Vol. 56 Part A March, pp. 3848. 
Keller, K.L., Kuilema, L.G., Lee, N., Yoon, J., Mascaro, B., Combes, A.L., Deutsch, B., Sorte, K. and Halford, J.C. (2012), "The impact of food branding on children's eating behavior and obesity", Physiology and Behavior, Vol. 106 No. 3, pp. 379-386.

Kennon, L. R. and Reynolds, J. S. (2001), "A study of factors influencing parental patronage", Journal of Restaurant and Food Services Marketing, Vol. 4 No. 3, pp. 113-122.

Lee, K., Conklin, M., Bordi, P. and Cranage, D. (2016), "Restaurants' healthy eating initiatives for children increase parents' perceptions of CSR, empowerment, and visit intentions", International Journal of Hospitality Management, Vol. 59, No. 10, pp. 60-71.

McAlister, A.R. and Cornwell, T.B. (2010), Children's brand symbolism understanding: Links to theory of mind and executive functioning. Psychology and Marketing, Vol. 27 No. 3, pp.203-228.

Novak, P. K., Smailović, J., Sluban, B. and Mozetič, I. (2015), "Sentiment of emojis", PLOS ONE, Vol. 10 No. 12, e0144296, doi: 10.1371/journal.pone.0144296

Poti, J.M. and Popkin, B.M. (2011), "Trends in energy intake among US children by eating location and food source, 1977-2006”, Journal of the American Dietetic Association, Vol. 111 No. 8, pp. 1156-1164.

Powell, L.M., Nguyen, B.T. and Han, E. (2012), "Energy intake from restaurants: demographics and socioeconomics, 2003-2008", American Journal of Preventive Medicine, Vol. 43 No. 5, pp. 498-504.

Robinson, T.N., Borzekowski, D.L., Matheson, D.M. and Kraemer, H.C. (2007), "Effects of fast food branding on young children's taste preferences", Archives of Pediatrics and Adolescent Medicine, Vol. 161 No. 8, pp. 792-797.

Sacco, J., Lillico, H.G., Chen, E. and Hobin, E. (2016), "The influence of menu labelling on food choices among children and adolescents: a systematic review of the literature", Perspectives in Public Health, Vol. 137 No. 3, pp. 173 - 181.

Sepulveda, K.K., Beltran, A., Watson, K., Baranowski, T., Baranowski, J., Islam, N. and Missaghian, M. (2009), "Fruit and vegetables are similarly categorised by 8-13-year-old children", Public Health Nutrition, Vol. 12 No. 2, pp. 175-187.

Sherwood, N.E., Story, M., Neumark-Sztainer, D., Adkins, S. and Davis, M. (2003), "Development and implementation of a visual card-sorting technique for assessing food and activity preferences and patterns in African American girls", Journal of the American Dietetic Association, Vol. 103 No. 11, pp. 1473-1479.

Shonkoff, E.T., Anzman-Frasca, S., Lynskey, V.M., Chan, G., Glenn, M.E. and Economos, C.D. (2018), "Child and parent perspectives on healthier side dishes and beverages in restaurant kids' meals: results from a national survey in the United States", BMC Public Health, Vol.18 No.1:56. doi: 10.1186/s12889-017-4610-3 
Sliwa, S., Anzman-Frasca, S., Lynskey, V., Washburn, K., and Economos, C. (2016), "Assessing the availability of healthier children's meals at leading quick-service and fullservice restaurants", Journal of Nutrition Education and Behavior, Vol. 48 No. 4, pp. 242249.

Strauss, A. and Corbin, J. (1994), "Grounded theory methodology", in Denzin, N.K. and Lincoln, Y.S. (Eds.), Handbook of Qualitative Research, Sage, Thousand Oaks, CA, pp. 273285.

Tinsley, B. (2003), "How Children Learn to be Healthy", Cambridge University Press, Cambridge, UK.

Wansink, B. (2015), "Change their choice! Changing behavior using the CAN approach and activism research", Journal of Psychology and Marketing, Vol. 32 No.5, pp. 486 -500.

Watkins, L., Watkins, L., Aitken, R., Aitken, R., Thyne, M., Thyne, M., Robertson, K., Robertson, K., Borzekowski, D. and Borzekowski, D. (2017), Environmental influences on pre-schooler's understanding of brand symbolism. Marketing Intelligence and Planning, Vol. 35 No. 7, pp. 907-922.

Weller, S.C. and Romney, A.K. (1988), “Systematic Data Collection”, Sage Publications, Thousand Oaks, CA.

Wiseman, N. and Harris, N. (2015), "A systematic review of data collection techniques used to measure preschool children's knowledge of food and nutrition", Journal of Nutrition Education and Behavior, Vol. 47 No. 4, pp. 345-353. 


\section{List of figures and tables}

Figure 1. Images from the apple card sort. Image of a) whole apple, b) apple slices, c) bagged apple slices with no branding, and d) bagged apple slices with logo branding of either a generic cartoon character logo, or the McDonald's logo, or the Starbucks logo, or the Subway logo

Figure 2. Example images from the assorted food card sort (a full image card set is available from the authors)

Figure 3. Five-point visual emoticon scale for closed card sort

Figure 4. Cumulative scores of child responses to the apple card sort using the emoticon scale

Figure 5. Cumulative scores of child responses to assorted food card sort using the emoticon scale 


\section{Young Children's Perceptions of Branded Healthy Fast Food}

\section{Structured Abstract}

Purpose - This study examined the role of branding on healthy fast food items.

Design/methodology/approach - Twenty children (age 4 to 6) performed one open sort and four closed card sorts about food preferences, perceived healthiness, and perceived parental preferences, using branded and non-branded food image cards. Descriptive statistics were calculated and major themes were identified from the verbatim transcripts.

Findings - The children chose whole fruit over branded and bagged apple slices, stating whole fruit would be tastier, healthier, and more likely parents approved. When apples were sliced and bagged, perceived taste and healthiness perceptions were variable. Packaged foods were more challenging for the children to conceptualize. Presented with eight options, french fries were the favourite choice as the children did not believe fruit or vegetable side dishes should accompany a cheeseburger.

Research limitations/implications - Only children's perceptions and not actual eating behaviours were measured. It was a small sample $(n=20)$ with limited sample diversity that would not be representative of all children.

Practical implications - Packaging and branding a healthy food item with a fast food logo did not increase the item's appeal to the children. Branding healthy foods in this manner may not lead to increased consumption.

Originality/value - The impact of branding healthy items on very young children's perceptions has rarely been examined. Most of the research on branded food items has focused on high calorie processed foods. Using a card sort exercise allowed children, too young to read and write, to articulate similarities, differences, and motivations around food preferences.

Keywords Parents, Health, Children, Fast Food, Branding, Food Choice, Card Sort, McDonald's

Paper type Research paper 


\section{Introduction}

\section{Children and fast food}

The Quick Service Restaurant (QSR) industry (commonly referred to as the fast food industry) plays an important role in the dietary intake of children (Castro et al., 2016). The frequency with which children eat away-from-home food has been on the rise since the beginning of this century (Poti and Popkin, 2011; Powell et al., 2012). In the US, just over one third of children consume fast food on a given day, and one out of eight children obtain more than $40 \%$ of their daily calories from fast food (CDC, 2015).

French fries are the common default side dish for a child's fast food meal. Depending on the restaurant, alternative side dish options are often available such as apple slices, orange segments, and yogurts (Shonkoff et al., 2018). The fast food restaurant industry has responded to consumer pressure to introduce more healthy side options with children's meals (Anzman-Frasca et al., 2014; Lee et al., 2016), however, various studies have shown that consumer uptake of the healthier side options has been minimal (Dodds et al., 2014) and the majority of children's meals fail to meet current nutritional recommendations (Sliwa et al., 2016).

Increased autonomy for food decisions outside of the home accelerates after age six. Prior to age seven, parents remain the primary gate keeper of food related decisions, when the children have not yet entered the phase of more autonomous food choices (Tinsley, 2003). The majority of the published research on young children dining outside of the home has been focused on surveying school aged children rather than preschool aged children. However, many of a child's long-term eating habits are formed in the early years (Wansink, 2015). The first six years of life are a critical time in the development of food preferences, when parents have a key influencing role, and when established food preferences have long term implications as to what the child will continue to eat once they reach an age of food decision autonomy. There is sparse literature on consumer behaviour related to ordering for young children in fast food restaurants (Kennon and Reynolds, 2001) and menu labelling with calories has not been shown to shift ordering habits (Sacco et al., 2016). A better understanding is required of how current fast food meal options are viewed. This study aims to further the understanding children's perceptions, during this transitional age (4-6 years old), from shared decision making (parent/child) to independent decision making.

\section{Branded food}

Research has shown mixed results when examining branded food items and children's food preferences and consumption patterns. Gelperowic and Beharrell (1994) addressed the role of the packages appeal to children and mothers' purchase decisions for healthy food products. Hartman (2017) examined branded snack choices of children (age 8 to 11) and demonstrated that preference by product type is the greatest influence on children's snack purchase decisions. A child's liking of a brand determines whether a brand is successful at motivating a child of this age to choose a product.

Keller et al. (2012) tested decorating fruit and vegetable containers with stickers of cartoon characters and provided prizes for fruit and vegetable consumption. Parents were instructed to offer a fruit and/or vegetable of the child's choosing at meals (three times per day) and 
one additional offer at snack time to the children $(n=7)$ (age 4 to 5 ). A measured increase in fruit and vegetable consumption was observed under these stringent conditions.

Robinson et al. (2007) demonstrated that branding could change a child's taste perceptions. Sixty-three children (age 3 to 5) took part in a tasting experiment. Results indicated that they were more likely to prefer the taste of chicken nuggets, french fries, milk, apple juice and carrots, if they were branded McDonald's, compared to unbranded identical foods.

Food marketing is primarily used to promote energy-dense, nutrient-poor foods. With children as young as 4 years of age able to recognize brands (McAlister and Cornwell, 2010; Watkins et al., 2017), and branded products having been shown to influence food preferences, it was of interest to study whether the branding used for fast foods could have a positive (or negative) impact on the perceptions of some healthy foods.

\section{Card sorts and food assessment with children}

Card sorts are used to explore how people organize and map objects and ideas (Fincher and Tenenberg, 2005). When working with young children, who are not yet of an age when they can read or write fluently, a card sort exercise is easy to administer, has a short learning curve, does not require literacy skills, and is an engaging process for children (Wiseman and Harris, 2015). Card sorts have been used with young children to demonstrate how they characterize foods from their own perspectives (Wiseman and Harris, 2015; Adams and Savage, 2017).

While this technique limits participants to the items depicted in the card deck, including an open sort (no structured categories) with the closed sorts (structured categories), it allows for the children to freely categorize the items into their own groupings, providing grounded insights into how the cards cluster. Card sorts, in food research with children, are one approach to understand how children categorize foods (Beltran et al., 2008; Sepulveda et al., 2009; Weller and Romney, 1988). While some research has looked at children aged 8 to 11, and tied product type, brand, and pricing together (Hartmann et al., 2017), less research has been conducted with younger children (aged 4 to 6 ), for whom the images of the options may be more influential.

The goal of this exploratory study was to examine young children's perspectives of branded and unbranded foods, by using card sorts, to explore how they categorize the foods, and to evaluate and describe their choices. Understanding the role that branding healthy food items may play, could help in the promotion of healthy side dishes for children in fast food restaurants.

\section{Methods}

\section{Respondents}

A total of 20 children (age 4 to 6 ) participated in the study. They were recruited from a convenience sample in Toronto, Canada, in 2017. The sample size was limited to 20, at which no new themes appeared to be emerging. Eligibility criteria included no dietary restrictions and a familiarity with eating in fast food restaurants. One parent of each participant provided written informed consent and at least one parent was present during the card sort exercise. The research was conducted in the participant's home, to provide the 
child with a familiar environment. Parents provided a quiet space for the interview, either at the dining room table or on the floor of the living room. Space was cleared so that the child had ample room to sort the cards. Distractions were minimized (no TVs, tablets, or music playing), with no branded food items within line-of-sight. During the card sort exercise, a parent was within viewing distance of the child, but out of the child's line of sight, to minimize parental influence. No participation incentive was provided. The study was approved by the $<$ University Name to be added after blinded peer review process> University Research Ethics Board.

\section{Background}

The card sorts were used to assess children's perceptions of branded and unbranded healthy food items. This study is a part of a larger ongoing project investigating family dining practices in fast food restaurants.

\section{Card design and sort}

Two card decks were developed by the researchers and the cards were pilot tested with two children. Cards were colour-printed on laminated card stock $(8 \mathrm{~cm} \times 8 \mathrm{~cm})$. Cards were sized to be easy for a 4 to 6 -year-old child to hold and sort. The card sort activity involved the child sorting a deck of cards that were pre-printed with photos of food items. Cards were sorted into an open sort first (with groups created by the child) and then into a series of closed sorts (with groups predetermined by the researcher).

\section{Card sort deck one}

The first card sort deck was a single food item (an apple) in seven forms. There were three unbranded formats: a whole apple, apple slices, and apple slices in an opaque snack sized unbranded bag and four branded apple slices in opaque snack sized bags (Figure 1).

$<$ Fig.1>

The opaque bag format was chosen as it is a common format for selling apple slices in fast food restaurants and in grocery stores in Canada, and the children would be familiar with this format. Five options were included in the apple slices-in-a-bag format, including: unbranded (labelled "Apples Slices"), one with a generic cartoon apple logo, and three versions using common QSR brands that have offered apple-in-a-bag options. These were McDonald's, Starbucks, and Subway. The design of the apple slices-in-a-bag images were identical, except for the logo.

\section{Card sort deck two}

The second card sort deck was comprised of nine different common food items. Examples of the cards are shown in Figure 2.

$<$ Fig.2>

The items chosen were common offerings available in fast food children's meals: whole apple, sliced apple, whole orange, orange segments, baby carrots, cheeseburger, french fries, yogurt cup. The images were designed to be comparable in perceived size. For example, there were seven slices of apple on the card with the apple slices on it, which is the equivalent of one whole apple, and on the card with the baby carrots, there were also seven baby carrots, so that the number of food pieces did not bias the response. In addition, an image of brussels sprouts was included in the deck. While brussels sprouts are not 
offered in a fast food child's meal, the image was intended to provide an anchor point of reference for the child.

Visual scale

A third series of cards (Figure 3) was used for the closed card sorts, to provide participants with a visual hedonic response scale.

$<$ Fig.3>

This response option was designed based on commonly used scales for this purpose (ASTM E2299-03) appropriate for children and easy to understand. Emoticons have become popular worldwide on smartphones, social media, and email applications (Novak et al., 2015). Jaeger et al. (2017) demonstrated that emojis can be used to measure the appreciation of foods in a subjective, non-verbal manner. Gallo et al. (2017) demonstrated that children can use a combination of emotion words and emojis to describe their reactions to foods. A scale of emoji-type faces is not new to food research with children, as over 20 years ago, Chen et al. (1996) used a version of this scale to study food preferences in young children. A 5-point scale of emoticon faces was used to represent a 5-point measurement scale for the closed card sorts. For each of the four closed sorts, the interviewer identified what the ends of the scale represented, for example, for the first closed sort, children sorted food based on what they thought tasted 'good/yummy' to food they thought tasted 'not good/yucky'.

Interviews

During the interviews, participants completed a series of five card sorts per deck, 10 sorts in total. Five sorts were completed with deck one, followed by five sorts with deck two. Given the young age of the participants, the number of cards was intentionally limited, and the length and depth of the interview was guided by the engagement of the child.

The interview began with an open sort, with no structured categories, followed by four sorts with closed categories. The five sorts were as follows.

1. Open methods sort: the child sorted the food cards into groups of their choice.

After the open methods sort, for the closed sorts, the visual scale was added to the work space to assist the child in the sort.

2. Closed methods sort: the child sorted the food cards into piles based on taste (best taste to worst taste).

3. Closed methods sort: the child sorted the food cards into piles based on perceived healthiness (most healthy to least healthy).

4. Closed methods sort: the child sorted the food cards into piles based on what they thought their mother would like them to eat (mom wants me to eat this to mom does not want me to eat this).

5. Closed methods sort: the child was asked if they had a second adult in their home living with them (for example, a father, a second parent). If there was a second adult in the child's home, the child was asked to sort the food cards into piles based on what the other adult might like them to eat (they want me to eat this to they do not want me to eat this). 
The cards were shuffled to achieve a random order prior to each sort. Any questions that the children had about the cards were answered by the interviewer (for example, confirming that each depicted bag had the same number of apple slices in it). For the open sort, the children could create as many or as few piles as they wanted, and a pile could have only one item if that was what the child wanted. After sorting, the interviewer asked the child to describe each pile they had created. The interview was audio recorded. Photos were taken of each card sort. The photos captured how the cards were sorted on the table and the photos were added to the field notes. No identifying characteristics of the participants were captured. After the interview, the audio file was transcribed and the sort order was captured from the field photos. Conducting the card sorts took 10 to 22 minutes per child.

\section{Analysis}

For the open methods sort, participant-described categories were compiled and coded for emergent themes and concepts. Participant comments from the transcription were reviewed to ensure that the development of the themes was consistent with the participants' descriptions.

For the closed sorts, descriptive statistics were calculated and the 5-point visual scale was converted to a quantitative score (1=Happy Face to $5=$ Unhappy Face) to allow for additional analytics. Frequency data and descriptive statistics for the card sort were calculated using SPSS version 24.

A grounded theory approach (Strauss and Crobin, 1994) was used to identify emerging themes from the verbatim transcripts. Participant quotes were chosen to describe each major theme, and were selected across a range of participants to ensure representation from the sample population.

\section{Results}

\section{Participants}

A total of 20 children participated in the study, 8 boys, 12 girls. Children were age 4 to 6 (mean age of 5.1 ( \pm 0.9 ) years). The children were predominantly Caucasian $(80 \%)$, and most had two parents living at home (95\%).

Deck one card sort - apples

All children recognized and easily identified the whole apple and apple slices. While they did not necessarily recognize the brands on each bag of apple slices, they were able to recognize that it was a picture of a bag of something apple-related and that it came from a store or a restaurant.

\section{Open sort exercise}

During the unstructured card sort, children were instructed to sort the apple cards into piles of things that were the same and things that were different. The children could make as many or as few piles as they wished. The children after sorting the images of apples into similar and different foods were asked to explain their groupings; 18 of the 20 children completed an identical sort. The whole apple and the slices of apple were one group and all of the bagged apples were placed in a second group. The whole apple and sliced apple were identified as the same food, but it was not always clear to the children what was in the 
apple bags. From the perspective of the children, the apples in the bags, regardless of the brand, were distinctively different from the whole apple or apple slices not in a bag.

"Is it dried apples? Apple slices? Apple sauce? I can't tell. Only that it is different from these" [points to the whole apple and the non-bagged sliced apple] (male, 5 years old)

Closed sort exercise

Most children thought that they would like the taste of the whole and sliced apples and classified both as healthy food choices. The perceptions of the sliced apples in bags demonstrated variability, as to whether the children thought the slices would taste good, if the slices were healthy, and if the slices were something that they thought a parent would want them to eat. Results the card sort are presented Figure 4, with detailed tabulated scores available in Supplementary Table I.

$<$ Fig.4>

A cumulative score can be seen in Figure 4, in which the whole apple scores higher than all the other apple variations. Of note, the cartoon branded apple has an overall higher cumulative score than the unbranded apple, elevated by what the child perceives the parent's perception of it is.

\section{Themes}

The three major themes identified from the discussions during the closed apple card sort are outlined below. The study was limited to 20 respondents, since while reinforcing themes from previous interviews, with respondents 17 to 20 no new themes arose.

\section{Theme 1: Packaged apples in a bag are not the same as non-packaged apples}

Similar to the open sort, it was clear that apples in bags were different from apples that were not in bags.

"If they are in a bag they would taste different." (female, 6 years old)

"These look like they could come from a farm [points to whole apple and sliced apple] but you would not find these on a farm. These are from a store." (male, 6 years old)

\section{Theme 2: Brand sometimes influenced expected taste and experience}

The branded apple options included McDonald's, Starbucks, and Subway, as well as an unbranded version and a version with a generic happy cartoon apple on the bag. Many of the children recognized the McDonald's logo and the Starbucks logo, but very few recognized the Subway logo. Seeing the McDonald's logo, often led to comments about what other experiences McDonald's offered.

"McDonald's! You get toys there too. Cheeseburgers, french fries and toys!" (female, 4 years old) 
While some children recognized the Starbucks logo by name, most referred to it as a coffee shop. Associating a coffee shop with apples was often not an intuitive fit for the children. For some, this meant that the apples would likely have a coffee taste.

"Those apples would taste yucky [points to Starbucks branded apple slices] because I think there's coffee there too." (female, 6 years old)

One respondent, interpreted the word Subway, for the type of underground transportation known as a subway.

"Subway? Who would eat apples on the subway? That's gross." (male, 6 years old)

\section{Theme 3: Apples are healthy, except when they are not}

Most children categorized the apples as healthy and tasty. However, all apples were not equally healthy.

For the whole apple, the children were quick to identify it as healthy (90\%) and as something a parent would want them to eat. However, for branded apple slices, the distinction was not as clear.

"This apple is from McDonald's [places apple under the unhappy face] ...McDonald's doesn't have very good food... momma doesn't want me to eat McDonald's food." (female, 6 years old)

Deck two card sort - assorted foods

All children recognized and easily identified the food items, except for the brussels sprouts, which required clarification from the interviewer at times. The children recognized the brussels sprouts, but some could not remember the name of the food.

Open sort exercise

When asked to sort the food images into similar and different foods and to explain their groupings, a few common groupings were created by the majority of the children. Whole fruit was most often partnered with its segmented counterparts, for example the whole apple was most often grouped with the apple slices and the whole orange was most often grouped with the orange segments. The brussels sprouts were rarely grouped with other items. Children commented that nothing was similar to brussels sprouts. The cheeseburger was most often grouped with the french fries, and the interviewer probed further to see if other items might be associated with the cheeseburger, but additional groupings were not identified.

"French fries go with the cheeseburger." (female, 5 years old)

Interviewer: Could anything else go with the cheeseburger?

"No, when you go to a restaurant, you get french fries with your cheeseburger."

Interviewer: Do you ever get apple slices with a cheeseburger?

"No."

Interviewer: Do you ever get carrots with a cheeseburger?

"No, only french fries go with a cheeseburger." 


\section{Closed sort exercise}

Most children liked the fruit options and identified them as healthy. French fries were most often identified as a food the child thought tasted the best, with a variety of responses as to whether or not french fries were healthy. As expected, brussels sprouts received a strong response from the children. Brussels sprouts were often identified as a food that they would not like, but as a healthy item that at least one parent would want them to eat.

Results from the assorted food card sort are presented Figure 5, with detailed tabulated scores available in Supplementary Table SII.

$<$ Fig.5>

Looking at the cumulative scores (Figure 5), even though the french fries were the option chosen by most of the children, they were ranked as one of the lowest items in terms of 'would my parent want me to eat this?'. This may well create tension in negotiating what the child eats in a fast food restaurant.

The major themes identified from the discussions during the closed assorted food card sort are outlined below.

\section{Theme 4: Tasty and healthy are distinct concepts}

For the majority of the children, french fries were identified as the tastiest of the options and were frequently referenced as the chosen option of all of the food cards. But, the children were also clear that french fries were not as healthy as the fruit options and that at least one parent would likely want them to eat fruit more frequently than french fries.

"I love French fries. I want them every day." (male, 6 years old)

"French fries are not as healthy as fruit. But they are yummy." (female, 6 years old)

Theme 5: Nutrients

While the male respondents rarely mentioned specific nutrient elements of the food images, the female respondents frequently talked about the nutrients, what was in the food, and how that influenced their opinion.

"They [pointing to french fries and cheeseburgers] aren't healthy for you...because they use sugar in them. It's bad because it's not healthy for you." (female, 6 years old)

"Bread is made of sugar and it doesn't have any vegetables so it's not good for you...[pointing to french fries] these are a little bit healthier because it has potatoes in it". (female, 5 years old)

"French fries are not healthy cause of the salt...sometimes salt makes you sick or if you have too much salt you can pass out and never wake up again." (female, 6 years old)

\section{Theme 6: Children understand that their parents have different food perspectives}

For households with two parents, the children were asked to estimate what their mother would want them to eat, or not want them to eat. Then they were asked to do an additional sort reflecting what the second adult in their house would want them to eat or not want them 
to eat. Often, the second parent was portrayed by the child as having a much more lenient approach to eating.

"When I'm out with my dad, there's no chance of getting anything healthy...because when me and my dad are out we always have party time food... because when I'm out with him, he doesn't like having anything healthy." (female, 6 years old)

"Dad wants me to eat anything. He's just happy when I eat. It doesn't matter what it is." (male, 4 years old)

\section{Summary}

A conclusion from this study, similar to the conclusions by Adams and Savage (2017) on their snack study with this age group of children, is that we need a better understanding of young children's eating behaviour if we wish to target effective interventions for healthy eating. Althubaiti et al. (2017), looking at a wider range of ages (age 3 to 12) in a snack card sorting exercise, reported that when children were asked about their parent's snack choices for them, as in our study, they identified snacks that they perceived to be healthier. However, in their study, they observed that perceptions of healthier did not translate into the children's actual snacking behaviour and suggested that more nutrition education is required to encourage healthy choices.

Using a visual card-sorting approach, this study provides insights into young children's perceptions of branded food items offered in fast-food restaurants. Findings from the card sort revealed that children have a strong opinion of what food items will taste good, which items are healthy, and which items a parent might want them to eat and these classifications, while they may overlap, are distinct to them

Most children thought whole and sliced apples were a healthy food choice. Sliced apples in bags demonstrated variability not seen in whole or non-bagged apple slices, as to whether the children thought they would taste good, if they were healthy, and if they were something they thought a parent would want them to eat.

Whole fruit items were identified as healthy and tasting good. French fries and cheeseburgers were identified as tasting good, but with varied perceptions of health. For the children, it was more challenging to estimate how a packaged food would taste, if it was healthy and if parents would want them to eat it.

Brand logos influenced some of the children's perceptions on how a common food item would taste. However, the branding did not elevate the perception of the apple slices in the bags, in terms of taste or healthiness compared to the whole fruit.

Of the current options available for a child's meal at a fast-food restaurant, the majority of the children identified french fries as their chosen option. Regardless of the format of the fruit (whole, sliced, or branded apples or oranges), the perceived healthy items were not as appealing as the french fries, even less so once they were packaged. While the restaurants may be offering fruit side options in a child's meal, children as young as age 4 were pairing the french fries with the cheeseburger, and the majority did not pair fruit or vegetable options as naturally accompanying a cheeseburger. 
Typically, in a two-parent household, one parent had a more lenient approach to what their child should eat when dining out, and often the father was portrayed as more lenient.

Relatively few studies examine how branding might be used to increase the appeal of healthy foods among young children. This study adds to the limited body of literature in the under-researched area of parental interactions with young children ( $\leq 6$ years old) regarding fast food ordering decisions. Understanding how children perceive foods branded as healthy items and meal options in fast-food restaurants, provides a foundation for future research to better understand children's eating behaviour and how to develop more effective targeted interventions to encourage healthy choices. Additional research is needed to understand how branded healthy food items vary in perception based on a child's ethnicity, nationality, and economic status.

\section{Limitations}

A limitation of the study was that only children's perceptions and not actual eating behaviours were measured. In addition, only a small number of children were interviewed. The children were primarily English-speaking, middle class Canadians. Therefore, not a representative geographical sampling. Findings might be different using a larger pool of children, where there is a greater diversity in terms of ethnicity and socioeconomic status. The sample size and limited diversity in the sample did not allow for analysis of the results by factors such as gender, ethnicity, or socioeconomic status.

\section{Practical implications}

Children were able to clearly articulate their thoughts on the food images, and to sort them based on the 5-point scale. Children as young as four were able to recognize a brand on food packaging and to differentiate between what they think tastes good and what they think is healthy. Some were able to start to describe nutrients. Packaging and branding a healthy food item with a fast-food logo did not increase the item's appeal to children. Understanding children's perceptions of branded healthy items can help in presenting healthier options to encourage their selection. Perhaps the goal of designing a 'healthy treat' could inform future product innovations, or future meal design could consider including a default healthy item and a small treat to offer a more balanced approach

\section{References}

Adams, E. L. and Savage, J. S. (2017)," From the children's perspective: What are candy, snacks, and meals?", Appetite, Vol. 116 Sept., pp. 215-222.

Althubaiti, H., Hambly, C., Mitchell, S. E. and Speakman, J. R. (2017), "Children's perception on healthy snacks using a card sorting exercise in Aberdeenshire nursery and primary schools", Proceedings of the Nutrition Society, Vol. 76 (OCE2): E39, doi:10.1017/S0029665117000957

Anzman-Frasca, S., Dawes, F., Sliwa, S., Dolan, P.R., Nelson, M.E., Washburn, K. and Economos, C.D. (2014), "Healthier side dishes at restaurants: an analysis of children's 
perspectives, menu content, and energy impacts", International Journal of Behavioral Nutrition and Physical Activity, Vol. 11 No. 1: 81, https://doi.org/10.1186/1479-5868-11-81

ASTM E2299-03. (2003), "Standard Guide for Sensory Evaluation of Products by Children", ASTM International, West Conshohocken, PA.

Beltran, A., Sepulveda, K.K., Watson, K., Baranowski, T., Baranowski, J., Islam, N. and Missaghian, M. (2008), "Grains are similarly categorized by 8- to 13-year-old children", Journal of the American Dietetic Association, Vol. 108 No. 11, pp. 1921-1926.

Castro, I.A., Williams, C.B., Madanat, H., Pickrel, J.L., Jun, H.J., Zive, M., Gahagan, S. and Ayala, G.X. (2016), "Food ordering for children in restaurants: multiple sources of influence on decision making", Public Health Nutrition, Vol. 19 No. 13, pp. 2404-2409.

CDC (Centers for Disease Control and Prevention) (2015), "Caloric intake from fast food among children and adolescents in the United States, 2011-2012", NCHS Data Brief No. 213, September, available at: https://www.cdc.gov/nchs/data/databriefs/db213.htm (accessed 14 December 2017).

Chen, A. W., Resurreccion, A. V. A. and Paguio, L. P. (1996), "Age appropriate hedonic scales to measure food preferences of young children", Journal of Sensory Studies, Vol. 11, No. 2, pp. 141-163.

Dodds, P., Wolfenden, L., Chapman, K., Wellard, L., Hughes, C. and Wiggers, J. (2014), "The effect of energy and traffic light labelling on parent and child fast food selection: a randomised controlled trial", Appetite, Vol. 73 Feb., pp. 23-30.

Fincher, S. and Tenenberg, J. (2005), "Making sense of card sorting data", Expert Systems, Vol. 22 No. 3, pp. 89-93.

Gallo, K. E., Swaney-Stueve, M. and Chambers, D. H. (2017), "A focus group approach to understanding food-related emotions with children using words and emojis", Journal of Sensory Studies, Vol. 32 No. 3, e12264, doi: 10.1111/joss.12264

Gelperowic, R. and Beharrell, B. (1994), Healthy food products for children: Packaging and mothers' purchase decisions. British Food Journal, Vol. 96 No. 11, pp.4-8.

Hartmann, M., Cash, S. B., Yeh, C. H., Landwehr, S. C. and McAlister, A. R. (2017), "Children's purchase behavior in the snack market: Can branding or lower prices motivate healthier choices?", Appetite, Vol. 117 Oct., pp. 247 -254.

Jaeger, S. R., Vidal, L., Kam, K. and Ares, G. (2017), "Can emoji be used as a direct method to measure emotional associations to food names? Preliminary investigations with consumers in USA and China", Food Quality and Preference, Vol. 56 Part A March, pp. 3848. 
Keller, K.L., Kuilema, L.G., Lee, N., Yoon, J., Mascaro, B., Combes, A.L., Deutsch, B., Sorte, K. and Halford, J.C. (2012), "The impact of food branding on children's eating behavior and obesity”, Physiology and Behavior, Vol. 106 No. 3, pp. 379-386.

Kennon, L. R. and Reynolds, J. S. (2001), "A study of factors influencing parental patronage", Journal of Restaurant and Food Services Marketing, Vol. 4 No. 3, pp. 113-122.

Lee, K., Conklin, M., Bordi, P. and Cranage, D. (2016), "Restaurants' healthy eating initiatives for children increase parents' perceptions of CSR, empowerment, and visit intentions", International Journal of Hospitality Management, Vol. 59, No. 10, pp. 60-71.

McAlister, A.R. and Cornwell, T.B. (2010), Children's brand symbolism understanding: Links to theory of mind and executive functioning. Psychology and Marketing, Vol. 27 No. 3, pp.203-228.

Novak, P. K., Smailović, J., Sluban, B. and Mozetič, I. (2015), "Sentiment of emojis", PLOS ONE, Vol. 10 No. 12, e0144296, doi: 10.1371/journal.pone.0144296

Poti, J.M. and Popkin, B.M. (2011), "Trends in energy intake among US children by eating location and food source, 1977-2006", Journal of the American Dietetic Association, Vol. 111 No. 8, pp. 1156-1164.

Powell, L.M., Nguyen, B.T. and Han, E. (2012), "Energy intake from restaurants: demographics and socioeconomics, 2003-2008", American Journal of Preventive Medicine, Vol. 43 No. 5, pp. 498-504.

Robinson, T.N., Borzekowski, D.L., Matheson, D.M. and Kraemer, H.C. (2007), "Effects of fast food branding on young children's taste preferences", Archives of Pediatrics and Adolescent Medicine, Vol. 161 No. 8, pp. 792-797.

Sacco, J., Lillico, H.G., Chen, E. and Hobin, E. (2016), "The influence of menu labelling on food choices among children and adolescents: a systematic review of the literature", Perspectives in Public Health, Vol. 137 No. 3, pp. 173 - 181.

Sepulveda, K.K., Beltran, A., Watson, K., Baranowski, T., Baranowski, J., Islam, N. and Missaghian, M. (2009), "Fruit and vegetables are similarly categorised by 8-13-year-old children”, Public Health Nutrition, Vol. 12 No. 2, pp. 175-187.

Sherwood, N.E., Story, M., Neumark-Sztainer, D., Adkins, S. and Davis, M. (2003), "Development and implementation of a visual card-sorting technique for assessing food and activity preferences and patterns in African American girls", Journal of the American Dietetic Association, Vol. 103 No. 11, pp. 1473-1479.

Shonkoff, E.T., Anzman-Frasca, S., Lynskey, V.M., Chan, G., Glenn, M.E. and Economos, C.D. (2018), "Child and parent perspectives on healthier side dishes and beverages in restaurant kids' meals: results from a national survey in the United States", BMC Public Health, Vol.18 No.1:56. doi: 10.1186/s12889-017-4610-3 
Sliwa, S., Anzman-Frasca, S., Lynskey, V., Washburn, K., and Economos, C. (2016), "Assessing the availability of healthier children's meals at leading quick-service and fullservice restaurants", Journal of Nutrition Education and Behavior, Vol. 48 No. 4, pp. $242-$ 249.

Strauss, A. and Corbin, J. (1994), "Grounded theory methodology", in Denzin, N.K. and Lincoln, Y.S. (Eds.), Handbook of Qualitative Research, Sage, Thousand Oaks, CA, pp. 273285.

Tinsley, B. (2003), "How Children Learn to be Healthy", Cambridge University Press, Cambridge, UK.

Wansink, B. (2015), "Change their choice! Changing behavior using the CAN approach and activism research", Journal of Psychology and Marketing, Vol. 32 No.5, pp. 486 -500.

Watkins, L., Watkins, L., Aitken, R., Aitken, R., Thyne, M., Thyne, M., Robertson, K., Robertson, K., Borzekowski, D. and Borzekowski, D. (2017), Environmental influences on pre-schooler's understanding of brand symbolism. Marketing Intelligence and Planning, Vol. 35 No. 7, pp. 907-922.

Weller, S.C. and Romney, A.K. (1988), "Systematic Data Collection", Sage Publications, Thousand Oaks, CA.

Wiseman, N. and Harris, N. (2015), "A systematic review of data collection techniques used to measure preschool children's knowledge of food and nutrition", Journal of Nutrition Education and Behavior, Vol. 47 No. 4, pp. 345-353. 


\section{List of figures and tables}

Figure 1. Images from the apple card sort. Image of a) whole apple, b) apple slices, c) bagged apple slices with no branding, and d) bagged apple slices with logo branding of either a generic cartoon character logo, or the McDonald's logo, or the Starbucks logo, or the Subway logo

Figure 2. Example images from the assorted food card sort (a full image card set is available from the authors)

Figure 3. Five-point visual emoticon scale for closed card sort

Figure 4. Cumulative scores of child responses to the apple card sort using the emoticon scale

Figure 5. Cumulative scores of child responses to assorted food card sort using the emoticon scale 

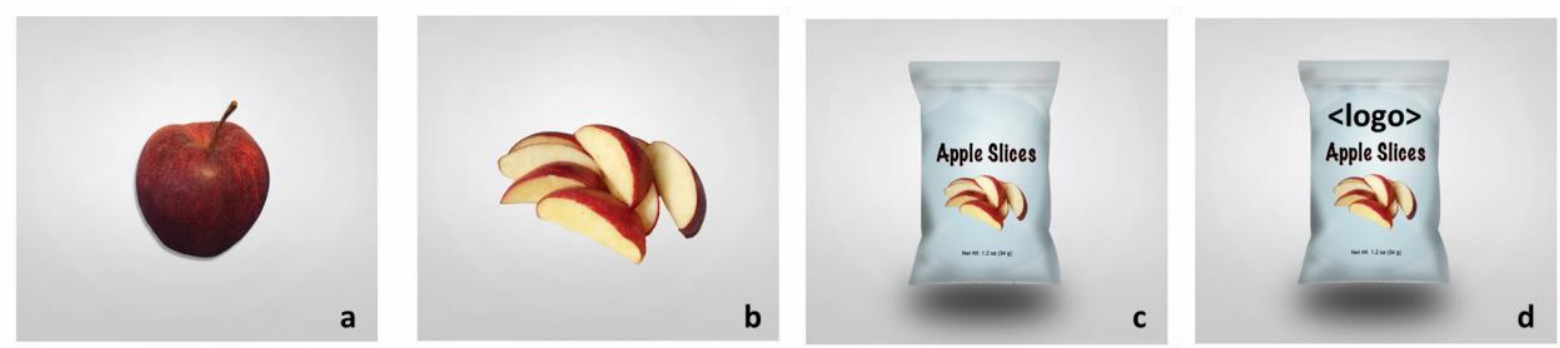

Figure 1. Images from the apple card sort. Image of a) whole apple, b) apple slices, c) bagged apple slices with no branding, and d) bagged apple slices with logo branding of either a generic cartoon character logo, or the McDonald's logo, or the Starbucks logo, or the Subway logo 

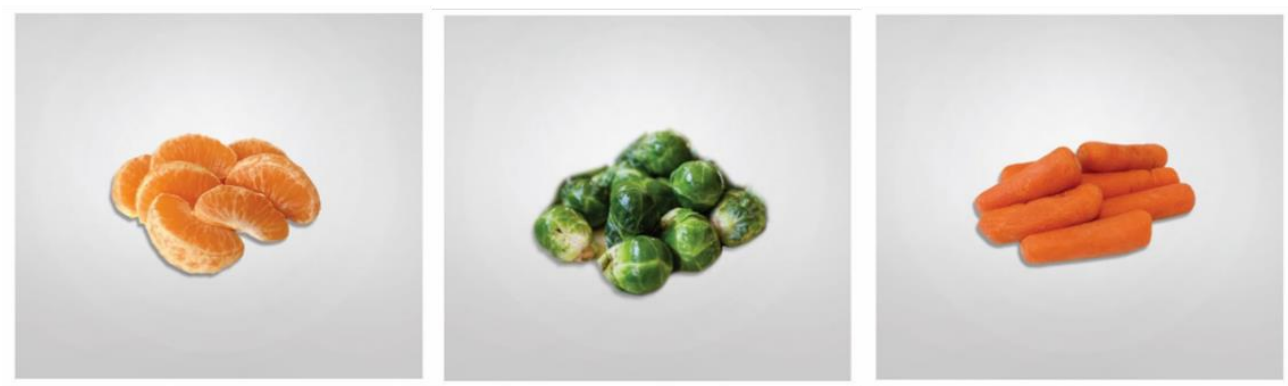

Figure 2. Example images from the assorted food card sort (a full image card set is available from the authors) 


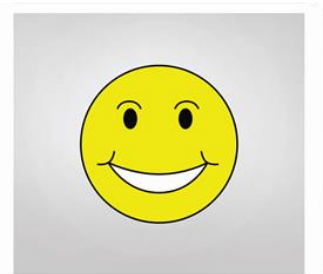

1

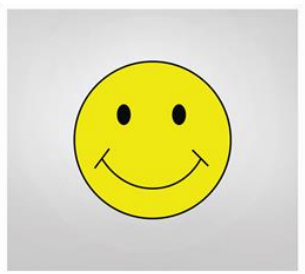

2

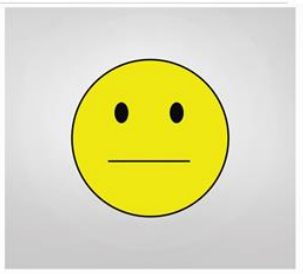

3

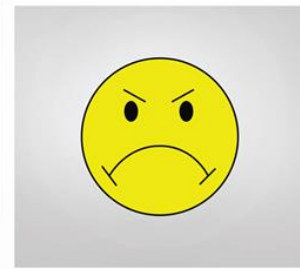

4

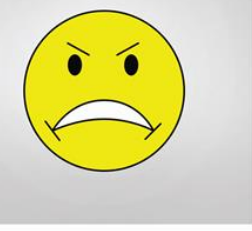

5

Figure 3. Five-point visual emoticon scale for closed card sort 


\section{Apple Card Sort Cumulative Scores}

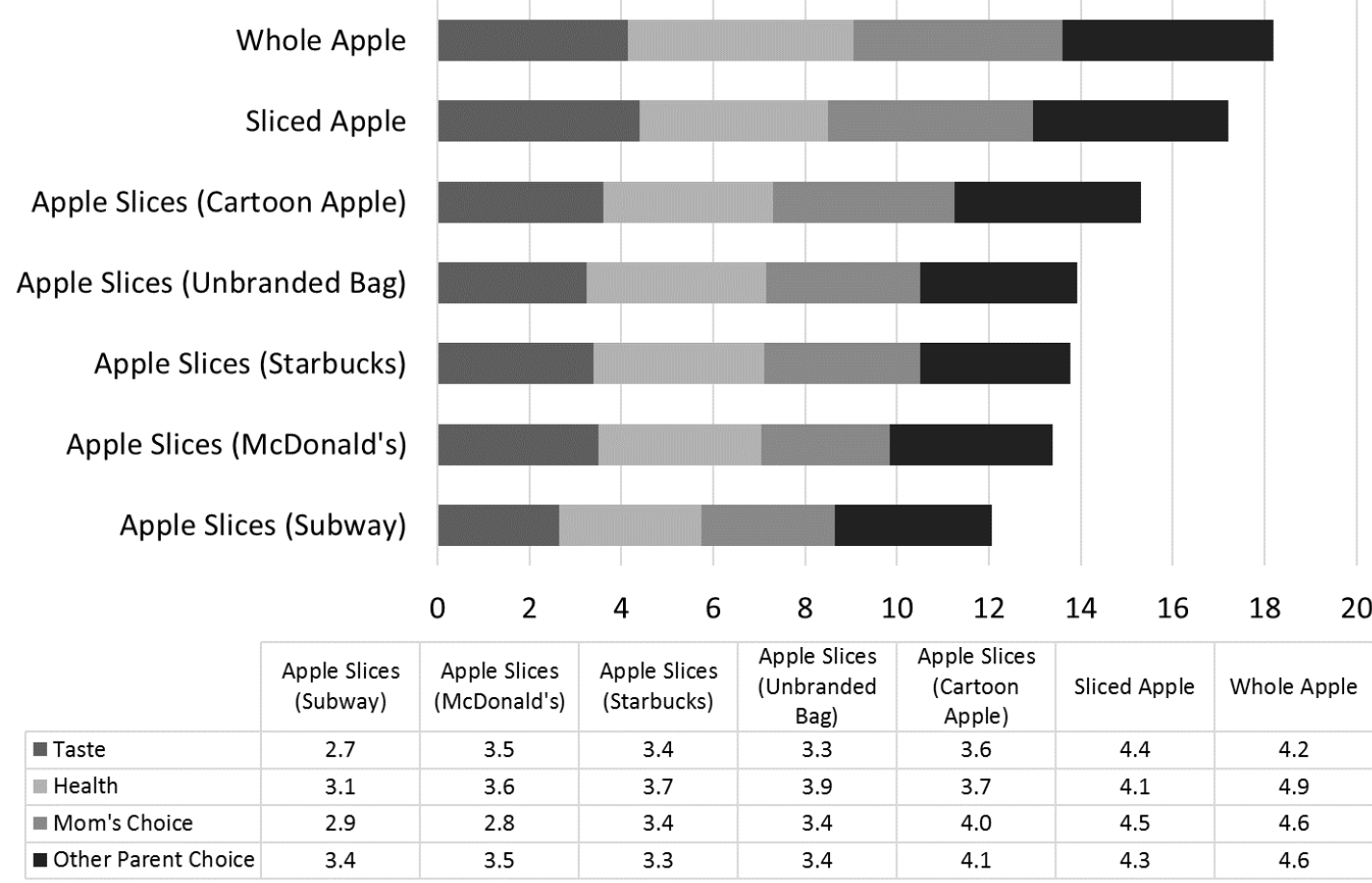

Figure 4. Cumulative scores of child responses to apple card sort using the emoticon scale. Scores were calculated as a total score summing the emoticon scale as a 5 -point scale where responses to questions were: $5=$ most positive, $4=$ positive, $3=$ neutral, $2=$ negative, $1=$ most negative 
Figure 5. Cumulative scores of child responses to assorted food card sort using the
emoticon scale. Scores were calculated as a total score summing the emoticon scale as
point scale where responses to questions were: $5=$ most positive, $4=$ positive, $3=$ neutral

Figure 5. Cumulative scores of child responses to assorted food card sort using the
emoticon scale. Scores were calculated as a total score summing the emoticon scale as a 5-
point scale where responses to questions were: $5=$ most positive, $4=$ positive, $3=$ neutral,

Figure 5. Cumulative scores of child responses to assorted food card sort using the
emoticon scale. Scores were calculated as a total score summing the emoticon scale as
point scale where responses to questions were: $5=$ most positive, $4=$ positive, $3=$ neutral, $2=$ negative, $1=$ most negative

\section{Assorted Food Card Sort Cumulative Scores}

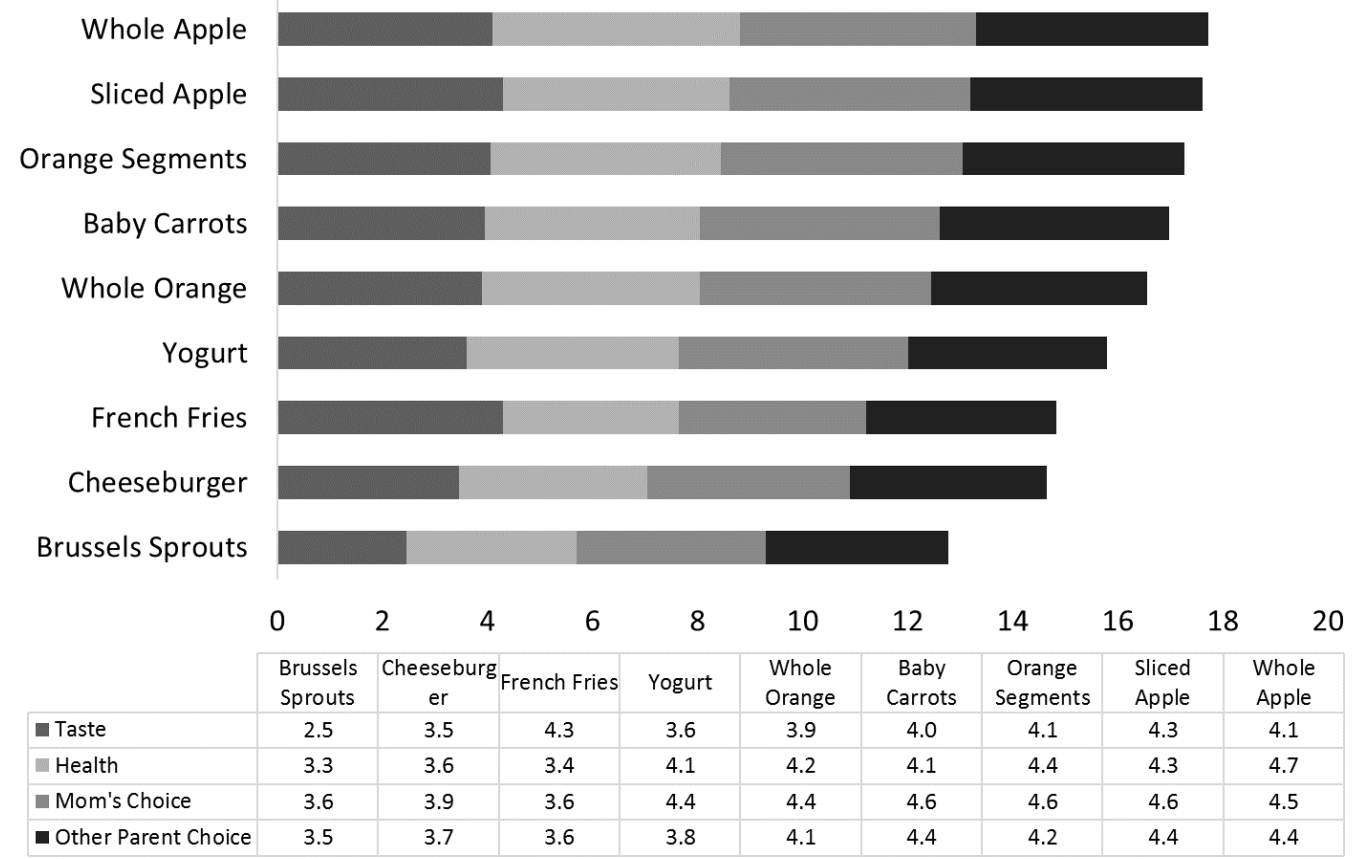




\section{Supplementary}

Supplementary Table SI. Child responses to apple sort using the emoticon scale

\section{Food Card}

\section{Taste Scores}

Whole Apple

Sliced Apple

Sliced Apple-in-a-Bag (Unbranded)

Sliced Apple-in-a-Bag (Cartoon Apple)

Sliced Apple-in-a-Bag (McDonald's)

Sliced Apple-in-a-Bag (Starbucks)

Sliced Apple-in-a-bag (Subway)

Healthy Scores

Whole Apple

Sliced Apple

Sliced Apple-in-a-Bag (Unbranded)

Sliced Apple-in-a-Bag (Cartoon Apple)

Sliced Apple-in-a-Bag (McDonald's)

Sliced Apple-in-a-Bag (Starbucks)

Sliced Apple-in-a-Bag (Subway)

Mom would choose for child to eat

Whole Apple

Sliced Apple

Sliced Apple-in-a-Bag (Unbranded)

Sliced Apple-in-a-Bag (Cartoon Apple)

Sliced Apple-in-a-Bag (McDonald's)

Sliced Apple-in-a-Bag (Starbucks)

Sliced Apple-in-a-Bag (Subway)

Other parent/adult would choose for child to eat ${ }^{b}$

Whole Apple

Sliced Apple

Sliced Apple-in-a-Bag (Unbranded)

Sliced Apple-in-a-Bag (Cartoon Apple)

Sliced Apple-in-a-Bag (McDonald's)

Sliced Apple-in-a-Bag (Starbucks)

Sliced Apple-in-a-Bag (Subway)
Score ${ }^{a}$

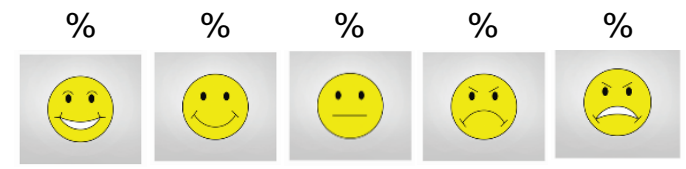

$\begin{array}{cccccc}4.2 & 12 & 3 & 2 & 2 & 1 \\ 4.4 & 12 & 5 & 2 & 1 & -- \\ 3.3 & 6 & 3 & 5 & 2 & 4 \\ 3.6 & 7 & 4 & 5 & 2 & 2 \\ 3.5 & 6 & 5 & 5 & 1 & 3 \\ 3.4 & 8 & 2 & 3 & 4 & 3 \\ 2.7 & 4 & 3 & 3 & 2 & 8 \\ 4.9 & 18 & 2 & -- & -- & -- \\ 4.3 & 12 & 4 & 1 & -- & 3 \\ 3.9 & 10 & 2 & 5 & 2 & 1 \\ 3.7 & 9 & 4 & 2 & 2 & 3 \\ 3.6 & 6 & 4 & 6 & 3 & 1 \\ 3.7 & 9 & 6 & -- & -- & 5 \\ 3.1 & 5 & 3 & 5 & 3 & 4\end{array}$

Notes: a Score was calculated as a total score summing the emoticon scale as a 5-point scale where responses to questions were: $5=$ most positive, $4=$ positive, $3=$ neutral, $2=$ negative, $1=$ most negative bFor the first three closed sorts, the sample size was 20 children. The last sort, based on 'other parent or adults in the household', had a sample size of 19 children. 
Supplementary Table SIl. Child responses to assorted food sort using the emoticon scale

\begin{tabular}{|c|c|c|c|c|c|c|}
\hline \multirow{2}{*}{ Food Card } & \multirow[t]{2}{*}{ Score $^{a}$} & $\%$ & $\%$ & $\%$ & $\%$ & $\%$ \\
\hline & & $\ddot{\theta}$ & (i) & $\stackrel{\ominus}{ }$ & $\dot{\circ}$ & $\stackrel{\bullet}{\ominus}$ \\
\hline \multicolumn{7}{|l|}{ Taste Scores } \\
\hline Whole Apple & 4.1 & 12 & 2 & 3 & 2 & 1 \\
\hline Sliced Apple & 4.3 & 12 & 4 & 2 & 2 & -- \\
\hline Whole Orange & 3.9 & 11 & 3 & 1 & 3 & 2 \\
\hline Orange Segments & 4.1 & 11 & 3 & 3 & 2 & 1 \\
\hline Baby Carrots & 4.0 & 9 & 5 & 3 & 2 & 1 \\
\hline Cheeseburger & 3.5 & 8 & 3 & 2 & 4 & 3 \\
\hline French Fries & 4.3 & 14 & 2 & 1 & 2 & 1 \\
\hline Yogurt Cup & 3.6 & 8 & 4 & 4 & -- & 4 \\
\hline Brussels Sprouts & 2.5 & 5 & 1 & 2 & 2 & 10 \\
\hline \multicolumn{7}{|l|}{ Healthy Scores } \\
\hline Whole Apple & 4.7 & 17 & 2 & -- & -- & 1 \\
\hline Sliced Apple & 4.3 & 14 & 1 & 3 & 1 & 1 \\
\hline Whole Orange & 4.2 & 13 & 2 & 1 & 3 & 1 \\
\hline Orange Segments & 4.4 & 13 & 3 & 3 & 1 & -- \\
\hline Baby Carrots & 4.1 & 13 & 2 & 2 & -- & 3 \\
\hline Cheeseburger & 3.6 & 10 & 3 & -- & 3 & 4 \\
\hline French Fries & 3.4 & 9 & -- & 5 & 1 & 5 \\
\hline Yogurt cup & 4.1 & 12 & 2 & 3 & 1 & 2 \\
\hline Brussels Sprouts & 3.3 & 10 & -- & 2 & 1 & 7 \\
\hline \multicolumn{7}{|c|}{ Mom would choose for child to eat } \\
\hline Whole Apple & 4.5 & 15 & 3 & -- & 1 & 1 \\
\hline Sliced Apple & 4.6 & 16 & 2 & 1 & -- & 1 \\
\hline Whole Orange & 4.4 & 14 & 2 & 3 & -- & 1 \\
\hline Orange Segments & 4.6 & 15 & 3 & 1 & 1 & -- \\
\hline Baby Carrots & 4.6 & 16 & 1 & 1 & 2 & -- \\
\hline Cheeseburger & 3.9 & 9 & 4 & 4 & 1 & 2 \\
\hline French Fries & 3.6 & 8 & 2 & 6 & 1 & 3 \\
\hline Yogurt Cup & 4.4 & 13 & 4 & 1 & 1 & 1 \\
\hline Brussels Sprouts & 3.6 & 12 & -- & 1 & 2 & 5 \\
\hline \multicolumn{7}{|c|}{ Other parent/adult would choose for child to eat ${ }^{b}$} \\
\hline Whole Apple & 4.4 & 15 & 1 & -- & 2 & 1 \\
\hline Sliced Apple & 4.4 & 15 & 1 & 1 & -- & 2 \\
\hline Whole Orange & 4.1 & 13 & 1 & 2 & -- & 3 \\
\hline Orange Segments & 4.2 & 13 & 2 & 1 & 1 & 2 \\
\hline Baby Carrots & 4.4 & 14 & 1 & 1 & 3 & -- \\
\hline Cheeseburger & 3.7 & 8 & 5 & 2 & 1 & 3 \\
\hline French Fries & 3.6 & 9 & 1 & 5 & 1 & 3 \\
\hline Yogurt Cup & 3.8 & 9 & 4 & 2 & 1 & 3 \\
\hline Brussels Sprouts & 3.5 & 10 & -- & 2 & 3 & 4 \\
\hline
\end{tabular}

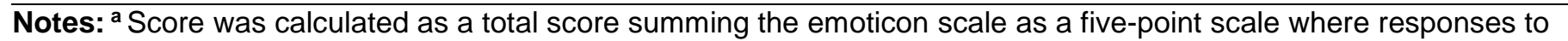
questions were: $5=$ most positive, $4=$ positive, $3=$ neutral, $2=$ negative, $1=$ most negative.

bFor the first three closed sorts, the sample size was 20 children. The last sort, based on 'other parent or adults in the household', had a sample size of 19 children. 


\section{British Food Journal}

BFJ-01-2018-0002

\section{Young children's perceptions of branded healthy fast food}

Original Paper submitted: 5 January 2018

Reviewer comments received: 23 January 2018

Response to reviewers: 27 January 2018

Revision due by 24 April 2018

\section{Response to Reviewers}

The authors thank the reviewers for their insightful and very helpful comments. All issues have been carefully addressed in the revised paper and detailed below. Insertions are also noted below.

\section{Response to Reviewer 1}

\section{General Comments}

This is an interesting paper using a novel, underused method to assess perceptions of branded foods in children. I have included my comments and suggestions for revision in the questions above. In general, I think the paper is worthy of publication, but there are some questions and concerns I have about the age of children and the environment for the testing.

Author Response: Thank-you. Your recommendations have been addressed below and in the revised version of the paper. We appreciate your advice to strengthen the paper and the time you took to provide the very thoughtful and helpful feedback.

\section{Originality:}

Does the paper contain new and significant information adequate to justify publication? This paper uses an original methodology (i.e., card sorting) to gather data on children's perceptions of branded foods. The topic is interesting and worthy of publication.

Author Response: Thank-you.

\section{Relationship to Literature:}

Does the paper demonstrate an adequate understanding of the relevant literature in the field and cite an appropriate range of literature sources? Is any significant work ignored?

The authors did a good job reviewing the previous literature and clearly articulating the gap in knowledge. No significant work is being ignored. 


\section{Methodology:}

Is the paper's argument built on an appropriate base of theory, concepts, or other ideas? Has the research or equivalent intellectual work on which the paper is based been well designed? Are the methods employed appropriate?

I'm unclear about the selection of sample size. Was the original intention to only get 20 kids? How did the authors know that after 20 kids, no new themes would arise? Did they initially collect data on more than 20 kids?

More information is needed about the pilot testing of the cards. Were these similar aged children? What types of questions were asked during the pilot, or what were the children required to do, and how did the researchers assess quality of the responses?

They did not clearly articulate why 4-6 year old children were selected. This is a large age range for children who are that young (quite a lot of cognitive differences between a 4 and a 6 year old). Were there any checks done to ensure that children understood what they were being asked to do? More information is needed about how the task was explained to children.

The experiments are carried out in the home, but the authors do not state how they made sure that other influences (e.g., TV, branded items in the home, foods in the home) were out of the way and did not influence children while they were doing the card sorting.

Author Response: Thank-you. We agree with the reviewer that additional information on the sample size, testing and background would strengthen the paper here, however, we wanted to ensure that our paper was within the word limit, and as such, elements of the paper are lean and we agree could use additional support.

Sample Size: When we reviewed these types of studies in the published literature, the answers varied greatly, but in general, the literature suggested that for a qualitative study of this nature, more than 10 interviews should take place. The original intent was to conduct the research with up to 20 children, pending review of the key themes identified by the children. If additional new themes were still arising, additional children would have been added to this qualitative study. However, by respondent 16, the main themes were being repeated. With respondents 17 through 20, while reinforcing themes from previous interviews, no new themes arose. Therefore, after the $20^{\text {th }}$ child, no additional interviews were conducted. The authors recognize that this is qualitative research, and with a larger sample size, additional themes may have surfaced, but a number of main themes have been identified with the sample size of 20 children. 
Inserted in text - The study was limited to 20 respondents, since while reinforcing themes from previous interviews, with respondents 17 to 20 no new themes arose.

Pilot Testing: The cards were tested with 4 children within the same age group $(4,5,6$, and 6 years old), to ensure that the task was easy to understand, that the cards were sized correctly, that the images were clear, the foods selected were recognizable and that the questions were reasonable for a child of this age group to answer. In pilot testing, similar aged children completed a full card sort, and the methodology was reviewed and revised to improve the data collection process.

Age Group: Card sort exercises have been used for other published research studies for this age group in the past. This methodology works well with children too young to read, but able to understand and articulate preferences. Food preferences can be established as young as 2-3 years old, and prior to age 7, children are young enough to not yet enter the phase of more autonomous food decisions, and the parent is still the primary gate keeper of food related decisions. The explanation of the task was tested in the pilot phase, revised and scripted. In addition, the interviewer answered any questions asked by the children during the cart sort exercise. In the study, the children appeared to easily understand the task, found it engaging, and were comfortable discussing their thoughts on the foods.

Location of Interviews: Interviews were conducted in the homes of the children. Parents provided a quiet space for the interview, either at the dining room table or on the floor of the living room. Space was cleared so that the child had ample room to sort the cards. Distractions were minimized (no TVs, tablets, or music playing), with no branded food items within line-of-sight. At least one parent was present, but removed from the immediate area. They could see their child, but the child could not easily see the parent (for example, a parent might have been across the room, but behind where the child was facing).

Inserted in text - Parents provided a quiet space for the interview, either at the dining room table or on the floor of the living room. Space was cleared so that the child had ample room to sort the cards. Distractions were minimized (no TVs, tablets, or music playing), with no branded food items within line-of-sight.

Results:

Are results presented clearly and analysed appropriately? Do the conclusions adequately tie together the other elements of the paper?

The results are clearly and adequately presented. Plus, the authors include supplementary data with all raw data, which is appreciated.

Author Response: Thank-you. 
Author Response: Thank-you. We agree that one of the limitations of the study is the sample size of 20 , and that the limited sample diversity is not representative of all children. We have included this limitation in the paper.

Inserted in text - Additional research is needed to understand how branded healthy food items vary in perception based on a child's ethnicity, nationality and economic status.

We also agree that there is an opportunity to expand more on the industry implications and we have added additional industry implications to the revised paper based on this helpful suggestion. Children age 4 to 6 seemed to already have a clear idea of what constitutes a "healthy" food item, and what they believe their mom (or other parent) would choose for them. Perhaps finding a 'healthy treat' could inform future product innovations, or approaches to meal design where a default healthy item and a small treat offer a more balanced approach.

Inserted into text - Perhaps the goal of designing a 'healthy treat' could inform future product innovations, or future meal design could consider including a default healthy item and a small treat to offer a more balanced approach

\section{Quality of Communication:}

Does the paper clearly express its case, measured against the technical language of the field and the expected knowledge of the journal's readership? Has attention been paid to the clarity of expression and readability, such as sentence structure, jargon use, acronyms, etc.

In general, the writing of the paper is clear, however, the introduction in particular could use better transitions between paragraphs and perhaps some editing to improve the focus. One example is the section on Card sorting where the paragraphs do not seem that logically ordered.

In general, more specificity is needed in language. For example, in the abstract, the authors stated that children preferred whole fruit over branded fruit, however, the methodology they used was not really a 
preference test. Therefore, I think it would be good if they carefully reviewed the terminology throughout to make sure they are using the terms according to what they actually tested.

Author Response: Thank-you. We agree that in the editing of the paper to reach the word count, some transitional statements were removed which previously helped the flow of the communication. We have now performed some additional editing of the paper to improve the flow in the first section and reviewed the use of terminology throughout the paper. The word 'preferred' has been replaced by 'chosen' in the abstract and text to avoid any confusion regarding a preference test.

\section{Response to Reviewer 2}

Author Response: Thank-you for your thoughtful and helpful comments and insights. We believe that we have addressed all concerns from your notes in the responses based on the limited number of words we are allowed to add to the paper and we will now have a clearer paper thanks to your help.

\section{General Comments}

This is a very interesting and generally well written report of a study which has yielded some useful findings. There is a minor phrasing problem on $p 7$, line 17"...elevated by what how the child perceives the parent's perceptions of it." Is there and AND missing between what and how?

$$
\text { p7, line 17, Typo noted and corrected. Thank-you. }
$$

The methods are clearly described as are the results. The summary at the end of the Results section is excellent.

However, the paper is incomplete at present as there is no discussion of the findings in relation to the existing literature and no clear statements about the implications of the findings in relation to future research directions.

A formal conclusion is also needed. This is a great pity, given the excellent literature review which cites a good deal of current research on children's food preferences. How does your work fit with this body of research? Your work on this age group is highly novel but to what extent is it congruent with other work on older children?

\footnotetext{
RE: The existing literature and this paper's connection to the additional literature

The work by Hartman et al. (2017), was discussed in the introduction on branding, where they examined branded snack choices of children (age 8 to 11), is extremely relevant to this topic and also captures literature in the area - but relating the two different age groups is a quandary for the discussion - as the question you so wisely raise is - what is the relationship when there is such
} 
The thematic analyses are really insightful but probably a little more could be done with the quantitative data, despite the small sample size. For example, non parametric correlation analysis might be used to estimate the extent to which the child's taste preferences are related to perceived parental preferences, for example.

We did examine the relationship between the child's preferences and the perceived parental preferences, but no statistically significant correlation was detected, with this limited sample size.

Re: findings in relation to future research directions. - Additional implications and future research direction have also been added.

Inserted in text - Additional research is needed to understand how branded healthy food items vary in perception based on a child's ethnicity, nationality, and economic status.

Inserted into text - Perhaps finding a 'healthy treat' could inform future product innovations, or approaches to meal design where a default healthy item and a small treat offer a more balanced approach. 


\section{Originality:}

Does the paper contain new and significant information adequate to justify publication?

Yes, this is novel work about the food preference of young children.

Author Response: Thank-you.

\section{Relationship to Literature:}

Does the paper demonstrate an adequate understanding of the relevant literature in the field and cite an appropriate range of literature sources? Is any significant work ignored?

A clear and concise literature review is provided which explains the need for the study and its significance.

Author Response: Thank-you.

\section{Methodology:}

Is the paper's argument built on an appropriate base of theory, concepts, or other ideas? Has the research or equivalent intellectual work on which the paper is based been well designed? Are the methods employed appropriate?

The theoretical basis of the study might be made a little clearer or stated more formally, though the phenomenological nature of the study is clear. The methods are clearly explained and illustrated.

Author Response: Thank-you.

\section{Results:}

Are results presented clearly and analysed appropriately? Do the conclusions adequately tie together the other elements of the paper?

The results are well described, though perhaps a little more analysis of the quantitative findings might be in order.

Author Response: Thank-you. While the findings were examined quantitatively, no statistically significant correlations were detected, likely influenced by the limited sample size. 
Implications for research, practice and/or society:

Does the paper identify clearly any implications for research, practice and/or society? Does the paper bridge the gap between theory and practice? How can the research be used in practice (economic and commercial impact), in teaching, to influence public policy, in research (contributing to the body of knowledge)? What is the impact upon society (influencing public attitudes, affecting quality of life)? Are these implications consistent with the findings and conclusions of the paper?

The implications of the findings for practical interventions are made clear though more thought might be given to follow-up research.

Author response: Thank-you. Additional implications and future research direction have been added as mentioned above.

\section{Quality of Communication:}

Does the paper clearly express its case, measured against the technical language of the field and the expected knowledge of the journal's readership? Has attention been paid to the clarity of expression and readability, such as sentence structure, jargon use, acronyms, etc.:

Generally the quality of the communication is excellent

Author Response: Thank-you. 